\title{
Altered Respiratory Motor Drive after Spinal Cord Injury: Supraspinal and Bilateral Effects of a Unilateral Lesion
}

\author{
Francis J. Golder, ${ }^{1}$ Paul J. Reier, ${ }^{2}$ and Donald C. Bolser ${ }^{1}$

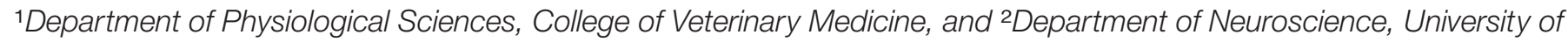 \\ Florida, Gainesville, Florida 32610
}

\begin{abstract}
Because some bulbospinal respiratory premotor neurons have bilateral projections to the phrenic nuclei, we investigated whether changes in contralateral phrenic motoneuron function would occur after unilateral axotomy via $\mathrm{C}_{2}$ hemisection. Phrenic neurograms were recorded under baseline conditions and during hypercapnic and hypoxic challenge in $\mathrm{C}_{2}$ hemisected, normal, and sham-operated rats at 1 and 2 months after injury. The rats were anesthetized, vagotomized, and mechanically ventilated. No group differences were seen in contralateral neurograms at 1 month after injury. At 2 months, however, there was a statistically significant decrease in respiratory rate (RR) at normocapnia, an elevated RR during hypoxia, and an attenuated increase in phrenic neurogram amplitude during hypercapnia in the $\mathrm{C}_{2}$-hemisected animals. To test whether $\mathrm{C}_{2}$ hemisection had induced a supraspinal change in respiratory motor drive, we recorded ipsilateral and contralateral hypoglossal neurograms during hypercapnia. As with the
\end{abstract}

High cervical spinal injuries in animal models and humans result in potentially life-threatening respiratory compromise because of the interruption of descending bulbospinal drive to either the phrenic motoneuron $(\mathrm{PhMN})$ pools directly (e.g., rat) (Ellenberger et al., 1990) or related interneurons (e.g., cat) (Bellingham and Lipski, 1990). However, the phrenic motor system can also exhibit a remarkable degree of functional plasticity, as best exemplified by the crossed phrenic phenomenon (CPP) (Goshgarian, 1981). Thus, a $\mathrm{C}_{2}$ hemisection axotomizes descending bulbospinal premotor neurons and creates a hemiparesis of the diaphragm. Restoration of phasic activity in the previously quiescent ipsilateral phrenic nerve may then occur either by inducing the CPP under controlled experimental conditions (O'Hara and Goshgarian, 1991) or by spontaneous expression of the CPP after a post-injury delay of 1-4 months (Nantwi et al., 1999). This functional recovery is believed to be mediated by activation of a latent bulbospinal premotor pathway that projects from the uninjured, contralateral side via decussations caudal to the hemisection (Moreno and Goshgarian, 1992). Serotonin is an important

Received June 28, 2001; revised Aug. 20, 2001; accepted Aug. 21, 2001.

This work was supported by the State of Florida Brain and Spinal Cord Injury Rehabilitation Trust Fund (F.J.G., D.C.B., P.J.R.), University of Florida Grinter Fellowship (F.J.G.), Mark F. Overstreet Fund for Spinal Cord Regeneration Research (P.J.R.), and National Institutes of Health Grant POI-NS-35702 (D.C.B., P.J.R.). We thank the Center for Human and Environmental Toxicology at the University of Florida for HPLC analytical services and Barbara O'Steen, Minnie Smith, Christine Pampo, Melanie Allen, Melissa Ruble, Julie Hammond, and Todd Klocker for technical assistance.

Correspondence should be addressed to Francis J. Golder, P.O. Box 100144, Gainesville, FL 32610-0144. E-mail: golderf@mail.vetmed.ufl.edu.

Copyright (C) 2001 Society for Neuroscience $\quad 0270-6474 / 01 / 210001-10 \$ 15.00 / 0$ phrenic motor function data, no change in hypoglossal output was evident until 2 months had elapsed when hypoglossal amplitudes were significantly decreased bilaterally. Last, the influence of serotonin-containing neurons on the injury-induced change in phrenic motoneuron function was examined in rats treated with the serotonin neurotoxin, 5,7-dihydroxytryptamine. Pretreatment with 5,7-dihydroxytryptamine prevented the effects of $\mathrm{C}_{2}$ hemisection on contralateral phrenic neurogram amplitude and normalized the change in RR during hypoxia. The results of this study show novel neuroplastic changes in segmental and brainstem respiratory motor output after $\mathrm{C}_{2}$ hemisection that coincided with the spontaneous recovery of some ipsilateral phrenic function. Some of these effects may be modulated by serotonin-containing neurons.

Key words: hypercapnia; hypoglossal; hypoxia; phrenic; rats; serotonin; spinal cord injury; ventilation

modulator of respiratory motor drive within both the brainstem and the phrenic nuclei (Bonham, 1995; McCrimmon et al., 1995) and has also been implicated in the expression of the CPP (Zhou and Goshgarian, 2000).

However, beyond the CPP and compensatory recruitment of other accessory respiratory muscles (e.g., intercostals), relatively little more is known of neurophysiological adaptations to cervical spinal cord injury (SCI) that may affect respiratory output from other segmental (i.e., contralateral phrenic) and supraspinal (i.e., hypoglossal) motor neuron pools. $\mathrm{C}_{2}$ hemisection has the potential to alter respiratory motor drive to the contralateral phrenic nucleus because some premotor neurons in the brainstem ventral respiratory group (VRG) extend bilateral descending collaterals to the $\mathrm{PhMN}$ pools (Lipski et al., 1994). $\mathrm{C}_{2}$ injury also may alter respiratory motor output from these motoneuron pools via serotonergic mechanisms after cervical deafferentation (Kinkead et al., 1998; Bach et al., 2000; Mantilla et al., 2000) or injury of respiratory raphe neurons with projections to both hypoglossal and the phrenic nuclei (Manaker et al., 1992).

For this study, we hypothesized that $\mathrm{C}_{2}$ hemisection would alter contralateral PhMN function and that serotonergic modulation could be involved. We also speculated that any effects of hemisection on contralateral phrenic motor output also would be manifested in the hypoglossal nerves. Our findings show that $C_{2}$ hemisection causes alterations in contralateral phrenic motoneuron output that entailed differential responses to specific physiological challenges. These changes on the uninjured side appeared to be partially modulated by serotonin-containing neurons. We also observed similar changes in respiratory motor output from 
both hypoglossal nerves along with a suggested alteration in the central respiratory pattern generator, as evidenced by a decreased baseline respiratory rate. Interestingly, the temporal emergence of these altered segmental and supraspinal functions overlapped with a low level of spontaneous ipsilateral PhMN functional recovery. Collectively, these findings provide novel insights into the functional neuroplasticity of the phrenic motor system that may be relevant to other motor systems and the development of therapeutic interventions for cervical spinal injuries.

\section{MATERIALS AND METHODS}

Seventy-three specific pathogen-free female rats were used in this study (Harlan Sprague Dawley, Indianapolis, IN) from colony K63317 and ranging in weight between 200 and $300 \mathrm{gm}$. The first set of experiments was designed to determine whether $\mathrm{C}_{2}$ hemisection alters the neurogram response to hypercapnia and hypoxia at 1 and 2 months after injury. Animals in this series were divided into three groups for each time point: at 1 month after injury: normal $(n=5), \mathrm{C}_{2}$ hemisected $(n=8)$, and sham-operated $(n=8)$; at 2 months after injury: normal $(n=8), \mathrm{C}_{2}$ hemisected $(n=15)$, and sham-operated $(n=12)$. Different rats were used to form the normal group for each time point. Either 1 or 2 months elapsed after surgical injury before rats were included in terminal electrophysiological studies. The second series of experiments explored whether serotonin is involved in any alterations in PhMN function after hemisection at 2 months after injury. Rats in this series were divided into two groups: 5,7-dihydroxytryptamine (DHT) pretreated $(n=7)$ and $\mathrm{C}_{2}$ hemisected and DHT pretreated rats $(n=10)$. Two months elapsed after surgical injury before these rats were included in terminal electrophysiological studies. HPLC and mass spectrometry were used to quantify the effect of DHT on monoamines within the brainstem and cervical spinal cords in normal $(n=2)$, sham-operated $(n=5), \mathrm{C}_{2}$ hemisected $(n=5)$, DHT-only $(n=5)$, and $\mathrm{C}_{2}$ hemisected and DHT $(n=5)$ rats. These rats were not included in terminal studies to assess respiratory drive; however, they were also allowed a 2 month postoperative survival period. Animal husbandry and all procedures were in compliance with the Institutional Animal Care and Use Committee at the University of Florida.

Spinal cord hemisection. Rats were anesthetized with medetomidine (75 $\mu \mathrm{g} / \mathrm{kg}, \mathrm{i} . \mathrm{m}$.) and isoflurane in oxygen anesthesia. After oro-tracheal intubation, anesthesia was maintained with isoflurane in oxygen, and rats were mechanically ventilated. A laminectomy was made at the $\mathrm{C}_{2}$ vertebral level, and the second cervical spinal segment and the cranial segment of the third cervical spinal segment were exposed. A 1-mm-long leftsided hemisection was then made in the cranial segment of $\mathrm{C}_{2}$ using a scalpel blade and the section aspirated with a fine-tipped glass pipette. The dura and arachnoid and overlying soft tissues were closed with interrupted 10-0 sutures. All animals were allowed to recover and received atipamezole $(0.1 \mathrm{mg} / \mathrm{kg}$, i.v. $)$ to antagonize the anesthetic effects of medetomidine, buprenorphine ( $50 \mu \mathrm{g} / \mathrm{kg}$, i.v.), and carprofen ( 5 $\mathrm{mg} / \mathrm{kg}$, i.v.) for postsurgery pain control. Analgesics were repeated as required over the next $2 \mathrm{~d}$. Either one or 2 months were allowed to elapse before rats were randomly placed in terminal electrophysiological studies. For rats that were sham-operated, the procedure was the same, but the spinal cord was left intact after the meninges were incised and sutured.

Administration of 5,7-dihyrdroxytryptamine. For the second series of experiments, rats were anesthetized with medetomidine ( $75 \mu \mathrm{g} / \mathrm{kg}$, i.m.) and isoflurane in oxygen anesthesia. After oro-tracheal intubation, anesthesia was maintained with isoflurane in oxygen, and rats were mechanically ventilated and placed in a stereotaxic apparatus. A 2-mmdiameter hole was drilled in the cranium immediately caudal to the bregma. The tip of a glass micropipette was positioned within the right lateral cerebral ventricle (coordinates: $0.8 \mathrm{~mm}$ posterior to the bregma, $1.5 \mathrm{~mm}$ lateral from the sagittal suture, and $3.5 \mathrm{~mm}$ ventral to the surface of the cerebral cortex). Thirty minutes after administration of the monoamine uptake inhibitor desipramine $(25 \mathrm{mg} / \mathrm{kg}$, i.p.), the selective serotonergic neurotoxin DHT (150 $\mu \mathrm{g}$ dissolved in $20 \mu \mathrm{l}$ of $0.2 \%$ ascorbic acid in normal saline) was injected slowly over 2 min using a pressure injection system. After drug injection, the micropipette was kept in position for an additional $5 \mathrm{~min}$ and then withdrawn. Rats were allowed to recover from anesthesia and received atipamezole $(0.1 \mathrm{mg} / \mathrm{kg}$, i.v. $)$ to antagonize the anesthetic effects of medetomidine and buprenorphine $(50 \mu \mathrm{g} / \mathrm{kg}$, i.v. ) and carprofen (5 mg/kg, i.v.) for postsurgery pain control.
One week was allowed to elapse after neurotoxin injection in rats that were to receive a $\mathrm{C}_{2}$ hemisection injury.

Assessment of respiratory motor drive. At either 1 or 2 months after injury, anesthesia was induced with urethane $(1.4 \mathrm{gm} / \mathrm{kg}$, i.p. $)$ and maintained with isoflurane in oxygen via a face mask. A femoral arterial catheter was placed to allow monitoring of direct arterial blood pressure and to allow collection of arterial blood for blood gas analysis (iSTAT, Waukesha, WI). Each blood gas measurement required $0.2 \mathrm{ml}$ of blood, and a maximum of four blood samples were taken from each rat. A femoral vein catheter was placed to administer drugs and fluids. Isoflurane was then discontinued, and anesthesia was maintained by administering urethane $(0.2-0.3 \mathrm{gm} / \mathrm{kg}$, i.v. $)$ as needed. Atropine $(0.1 \mathrm{mg} / \mathrm{kg}$, i.v.) was used to reduce airway secretions. At least 45 min elapsed from the end of isoflurane anesthesia until the start of baseline data collection. Animals were mechanically ventilated via a tracheotomy tube using a Harvard small animal ventilator. The rats were bilaterally vagotomized in the midcervical region and were paralyzed with pancuronium (1.0 $\mathrm{mg} / \mathrm{kg}$, i.v.). Both phrenic nerves were dissected within the caudal neck region (before the communication with the accessory phrenic nerve) using a ventral approach. In a subset of rats from each group, except those that received DHT, both hypoglossal nerves also were exposed in the cranial cervical region. The nerves were cut distally and placed over bipolar silver recording electrodes covered in a mixture of paraffin and mineral oil. Tidal volume was set at $2-2.5 \mathrm{ml}$. Body temperature was maintained at $37.5 \pm 0.5^{\circ} \mathrm{C}$ using an electric blanket.

Baseline conditions were standardized between groups by measuring the apneic threshold in an individual animal and setting the $\mathrm{PCO}_{2}$ at 2-3 $\mathrm{mmHg}$ above the apneic threshold. Apnea was accomplished by increasing the respiratory rate of the ventilator while monitoring the endtidal $\mathrm{PCO}_{2}$ (Capnoguard; Novametrix Medical Systems, Wallingford, CT). The apneic threshold was defined as the midpoint between the cessation of bursting and its reappearance once the respiratory rate was decreased. An arterial blood sample was then taken to measure the endtidal to arterial difference in $\mathrm{PCO}_{2}$. This difference was used to calculate the arterial $\mathrm{PCO}_{2}$ that corresponded to the apneic threshold. Rats were allowed $15 \mathrm{~min}$ at their baseline $\mathrm{PCO}_{2}$ to equilibrate before the protocol was started.

Stable baseline neurograms were recorded while the animal was ventilated with a hyperoxic gas mixture $\left(\mathrm{FiO}_{2}=0.40 ; \mathrm{FiCO}_{2}=0.00 ; \mathrm{FiN}_{2}=0.60\right)$. Animals were then challenged with $5 \mathrm{~min}$ of hypercapnia $\left(\mathrm{FiO}_{2}=0.40\right.$; $\left.\mathrm{FiCO}_{2}=0.05 ; \mathrm{FiN}_{2}=0.55\right)$ followed by $2 \mathrm{~min}$ of hypoxia $\left(\mathrm{FiO}_{2}=0.08\right.$; $\mathrm{FiCO}_{2}=0.00 ; \mathrm{FiN}_{2}=0.92$ ). At least $5 \mathrm{~min}$ was allowed between the successive challenges to enable respiratory activity (rate and amplitude) to return to baseline values. At the end of each challenge, an arterial blood sample was taken to measure blood gases before returning to baseline conditions. Before being killed, maximal eupneic inspiratory activity was induced by subjecting the animal to asphyxia by terminating mechanical ventilation. Peak inspiratory amplitude of eupneic-like bursts was measured to allow standardization of baseline inspiratory activity. Eupneic-like activity was differentiated from gasping using the criteria of St. John and Paton (2000). The raw neurograms were amplified, filtered $(0.2-2.0 \mathrm{kHz})$, recorded on VCR tape, and streamed online to a computer based data analysis system (CED 1401; Cambridge Electronic Design, Cambridge, UK).

Histological confirmation of $\mathrm{C}_{2}$ hemisection. After the asphyxic challenge, all rats that received a spinal hemisection were transcardially perfused with $4 \%$ paraformaldehyde solution in PBS. The cervical spinal cord was removed, and the $\mathrm{C}_{2}$ spinal segment was embedded in paraffin. The spinal segment was sectioned at $10 \mu \mathrm{m}$ thickness and stained with cresol violet and luxol fast blue. Complete hemisection of the second cervical spinal segment was confirmed by light microscopy.

Serotonin immunocytochemistry. The brainstem and midcervical spinal cord were also removed from rats that received a hemisection and/or DHT. A $2 \mathrm{~mm}$ transverse block from the brainstem (at the level of the area postrema) and one from the $\mathrm{C}_{4}$ spinal segment was sectioned on a vibratome at $40 \mu \mathrm{m}$ thickness. Sections were washed in high salt buffer, incubated in 5.0\% normal goat serum, and then incubated overnight in rabbit anti-serotonin. The sections were rewashed and then incubated for $45 \mathrm{~min}$ in goat anti-rabbit IgG. After being washed again, the sections were incubated in rabbit peroxidase anti-peroxidase for $45 \mathrm{~min}$. The sections were then reacted with $0.05 \%$ diaminobenzidine in the presence of hydrogen peroxide. The sections were then mounted and coverslipped. The sections were examined under light microscopy to determine the presence of serotonin immunoreactivity. Brainstem sections were examined under low magnification to identify the relative position of each 
section relative to the obex using a rat brain stereotaxic atlas. All brainstem sections were located between 0.7 and $2.7 \mathrm{~mm}$ rostral to the obex.

HPLC analysis. HPLC and mass spectrometry were used to quantify the effect of DHT on monoamines within the brainstem and cervical spinal cord in parallel groups of rats. Rats were decapitated at 2 months after injury, and their brainstem and entire cervical spinal cord were rapidly removed, weighed, and frozen to $-80^{\circ} \mathrm{C}$. Time from decapitation to placement in the freezer was consistently $<7 \mathrm{~min}$ for each animal. In preparation for analysis, each frozen sample was thawed on ice. To each thawed sample $2 \mathrm{ml}$ of $0.2 \mathrm{M}$ perchloric acid and $20 \mu \mathrm{l}$ of $125 \mu \mathrm{M}$ dihydroxybenzylamine were added. The sample was then homogenized on ice, centrifuged for $15 \mathrm{~min}$ at $4^{\circ} \mathrm{C}$, and filtered through a pipette containing a glass wool plug. To the collected supernatant $100 \mu \mathrm{l}$ of caffeine $(100 \mu \mathrm{g} / \mathrm{ml})$ was added as an internal standard, and the sample was transferred to an amber vial. Samples were analyzed by HPLC with mass spectrometric detection. The injection volume was $100 \mu \mathrm{l}$. Separation occurred across an AllTech $\mathrm{C} 18$ column under isocratic conditions in a flowing stream of 90:10 acetonitrile:ammonium acetate buffer (6.4 $\mathrm{gm} / 1$ ammonium acetate in water, $\mathrm{pH} 4.0$, with acetic acid). Sample handling from preparation to completion of analysis was maintained within an 18 hr time frame.

Data analysis. Bursting frequency [i.e., respiratory rate (RR)] and amplitude (AMP) were measured from the integrated hypoglossal neurograms and the integrated contralateral phrenic neurogram during baseline conditions and hypercapnia and hypoxia. Baseline RR and AMP were measured over $60 \mathrm{sec}$ and 10 bursts, respectively. During hypercapnia, RR and AMP were averaged from three adjacent bursts at the 60 sec time point and again at the $5 \mathrm{~min}$ end point. During hypoxia the intervals were $15 \mathrm{sec}$ and an end point measurement of $120 \mathrm{sec}$. The initial measurement during both challenges was taken to represent the dynamic component of the neurogram response and the end point measurement to coincide with sampling for blood gas analysis. Changes in RR and AMP were expressed as a percentage of baseline values. Baseline AMP was expressed as a percentage of asphyxic maximal amplitude as an additional standardization of baseline conditions within an animal.

Comparisons were performed of means using a two-factor ANOVA with repeated measures for time. When significant differences were found between groups, pairwise multiple comparisons were made using the Bonferroni's $t$ test. Differences in the incidence of observations made on the ipsilateral phrenic nerve between injured groups and controls were compared using the Fisher's exact test. Differences were considered significant if the overall significance level was $p<0.05$.

\section{RESULTS}

\section{Histological confirmation of $\mathbf{C}_{2}$ hemisection}

Based on the widespread distribution of descending axons from bulbospinal premotor neurons (Lipski et al., 1994), a unilateral deletion of VRG projection to the phrenic motoneuron pool requires complete removal of both the lateral and ventral funiculi. Thus, all the respiratory data reported below were obtained from animals with $\mathrm{C}_{2}$ hemisections that met histological criteria (Fig. 1). Only two $\mathrm{C}_{2}$ lesioned and one DHT pretreated and $\mathrm{C}_{2}$ injured rat were excluded from data analysis because the hemisections were either incomplete $(1 / 3)$ or had crossed the midline $(2 / 3)$.

\section{The contralateral phrenic neurogram after $\mathbf{C}_{2}$ hemisection}

\section{Baseline conditions}

During the prechallenge period, arterial blood gases and $\mathrm{pH}$, mean arterial blood pressure (MABP), heart rate, and rectal temperature were measured in all groups (Table 1). Normal and sham-operated rats were combined as "controls" because no significant differences were found between them in baseline variables or respiratory motor output during chemical challenge. When measurements from controls and $\mathrm{C}_{2}$ hemisected rats were compared at 1 and 2 months after injury, MABP, arterial $\mathrm{pH}$, $\mathrm{PaCO}_{2}, \mathrm{PaO}_{2}$, heart rate, and rectal temperature were identical (Table 1). Rectal temperature did not vary throughout the entire

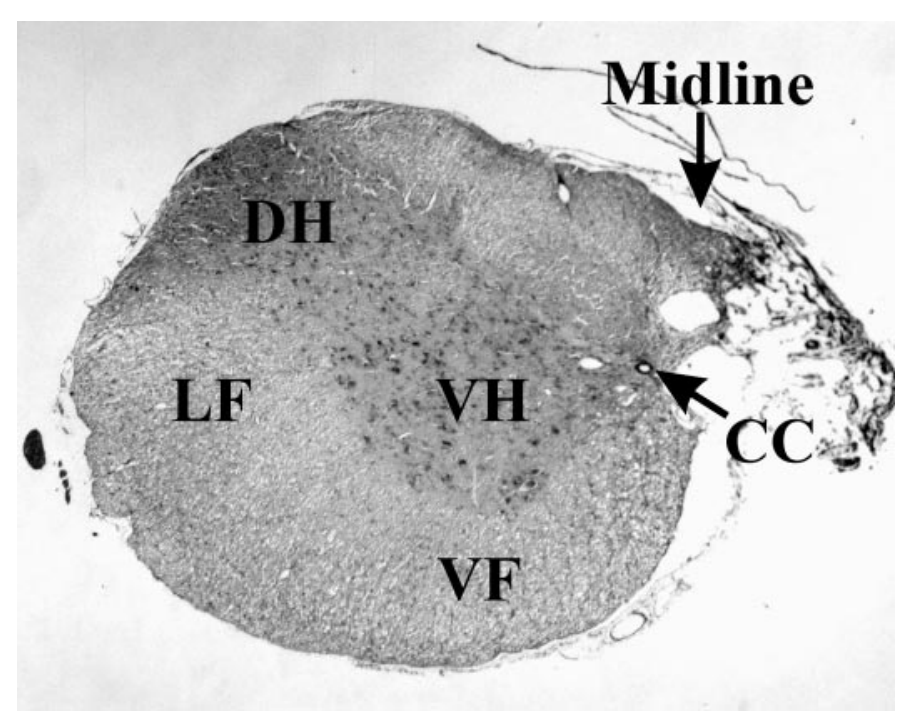

Figure 1. Photomicrograph of a $10 \mu \mathrm{m}$ transverse section through the cranial portion of the second cervical spinal segment. Notice complete hemisection with no spinal tissue remaining from the side of injury and the contralateral side remains intact. $L F$, Lateral funiculus; $V F$, ventral funiculus; $D H$, dorsal horn; $V H$, ventral horn; $C C$, central canal.

experiment. In addition, the apneic threshold measured in all rats at 1 month after injury and 14 of 20 control rats and 5 of $15 \mathrm{C}_{2}$ hemisected rats at 2 months after injury was similar between groups (Table 1).

Respiratory motor output was assessed by measuring phrenic $\mathrm{RR}$ and the peak amplitude of phasic activity in the right phrenic neurogram of controls and the phrenic neurogram contralateral to $\mathrm{C}_{2}$ injury in lesioned rats. Baseline contralateral phrenic neurogram amplitude was expressed as a percentage of the maximal amplitude in the same nerve during severe chemical challenge (as asphyxia at the end of the experiment) to standardize motor output (Nantwi et al., 1999). When expressed this way, baseline amplitude was similar between groups at both intervals after injury (Table 1$)$. In contrast, phrenic RR was significantly decreased $(p<0.05)$ in the $\mathrm{C}_{2}$ lesioned rats but only at 2 months after injury (Table 1, Fig. $2 c$ ).

\section{Hypercapnia}

We then exposed rats to hypercapnia for $5 \mathrm{~min}$ to stimulate respiratory motor drive because recently published evidence (Teng et al., 1999) suggests that the effects of SCI on ventilation may be more pronounced during respiratory challenge than eupnea. No differences were detected between control and lesioned groups at 1 or 2 months after injury in arterial blood gases, heart rate, or blood pressure during this challenge (see Table 3). Consistent with other studies (Fukuda and Honda, 1982; Kong and Berger, 1986; Bach and Mitchell, 1998; Bach et al., 1999), the response to hypercapnia in control rats consisted of an increased RR (Fig. 2a,c) and increased phrenic amplitude (Fig. 2b,d) above baseline values.

At 1 month after injury, no differences were detected in the hypercapnic neurogram response between controls and lesioned rats (Fig. 2a,b). By comparison, at 2 months after injury, the RR in $\mathrm{C}_{2}$ hemisected rats began at a lower rate (see above), but there were no differences in peak RR during hypercapnia compared with controls (Fig. 2c). The contralateral phrenic amplitude also increased during hypercapnia in $\mathrm{C}_{2}$ hemisected rats; however at 2 
Table 1. Baseline measurements at 1 and 2 months after injury

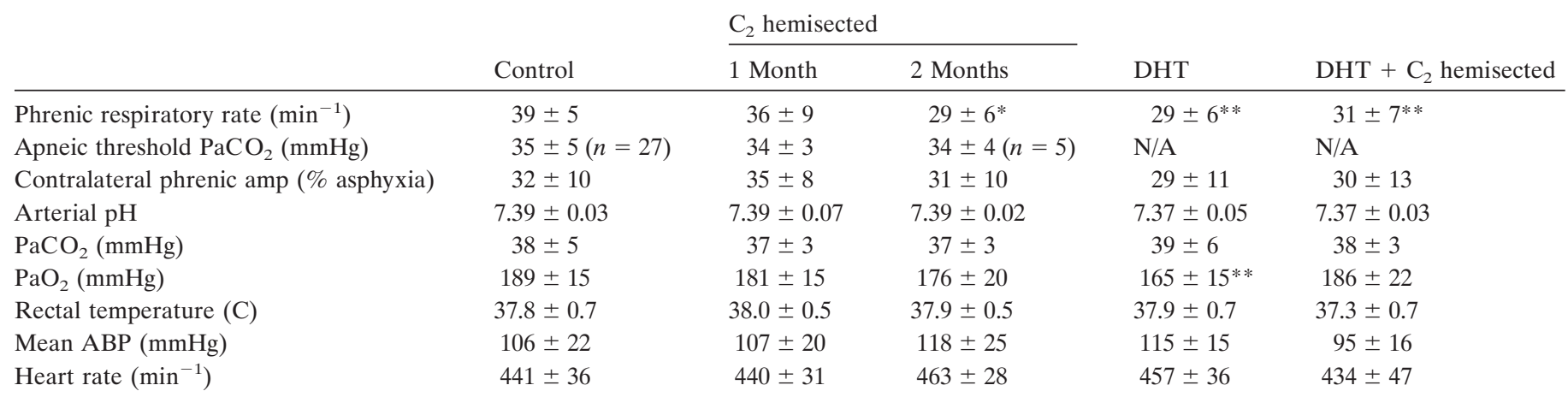

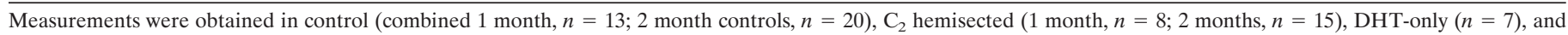
$\mathrm{DHT}+\mathrm{C}_{2}$ hemisected $(n=10)$ rats.

Means \pm SD. Amp, Amplitude; ABP, arterial blood pressure; DHT, 5,7-dihydroxytryptamine.

${ }^{*} p<0.01$ relative to control.

${ }^{* *} p<0.05$ relative to control.

N/A, Not measured.
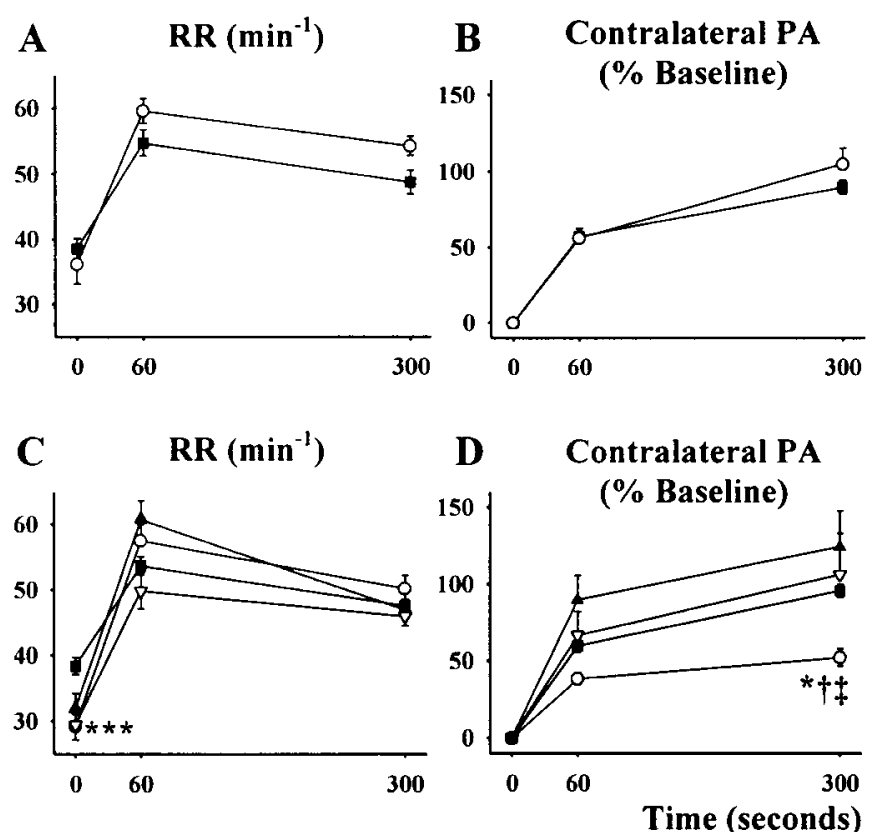

Figure 2. The contralateral phrenic neurogram response to hypercapnic challenge. The response to hypercapnia is presented at 1 month $(A, B)$ and 2 months $(C, D)$ after injury in control $(\square)$, DHT-only $(\nabla), \mathrm{C}_{2}$ hemisected $(\bigcirc)$, and DHT $+\mathrm{C}_{2}$ hemisected $(\mathbf{\Delta})$ rats. $A$ and $C$ represent the change in respiratory rate (RR) during 5 min of hypercapnia. $B$ and $D$ represent the percentage of increase in phrenic amplitude (PA) from baseline in the contralateral phrenic nerve. DHT, 5,7Dihydroxytryptamine. Means $\pm \mathrm{SE} ;{ }^{*} p<0.05$ relative to control; $\dagger p<$ 0.05 relative to DHT-only; $\ddagger p<0.05$ relative to hemisected + DHT.

months after injury, the maximal percentage change above baseline was only $\sim 50 \%$ of controls (Fig. $2 d$ ), thereby representing a significantly decreased amplitude response to chemical challenge $(p<0.05)$.

In previous studies, phrenic amplitudes during respiratory challenge have been expressed as a percentage of the phrenic maximal amplitude during extreme hypercapnic stimulation (Fregosi and Mitchell, 1994). This represents an attempt to reduce the large effect on a ratio when a small denominator (i.e., baseline amplitude) varies slightly. In our study, baseline amplitudes as a percentage of maximal asphyxic amplitude were comparable between groups (Table 1). Despite this, we chose to normalize the phrenic amplitude response to baseline amplitude because the hypercapnic amplitude response was abnormal in the $\mathrm{C}_{2}$ hemisected group and hypercapnia is a component of the asphyxic stimulus.

\section{Hypoxia}

After the hypercapnic challenge, rats were returned to baseline conditions, and at least 5 min elapsed before beginning the second chemical stimulus of $2 \mathrm{~min}$ of hypoxia. No differences were detected between control and lesioned groups at 1 or 2 months after injury in arterial blood gases, heart rate, or blood pressure during hypoxia (Table 2). During the hypoxic challenge, control rats responded as previously reported (Hoop et al., 1999; Bach and Mitchell, 2000) with an increase in RR (Fig. 3c) and phrenic amplitude (Fig. 3d).

At 1 month after injury no differences were detected in the hypoxic neurogram response between controls and lesioned rats (Fig. 3a,b). However by 2 months after injury, RR was lower than controls immediately before hypoxic challenge (Fig. $3 c$ ) and was similar to the effect of injury on RR during baseline conditions (Table 1, Fig. 2c). During hypoxia, RR was significantly higher in $\mathrm{C}_{2}$ hemisected rats compared with controls $(p<0.05)$ (Fig. $\left.3 c\right)$. In contrast to the hypercapnic challenge, no differences were identified in the contralateral phrenic amplitude response to hypoxia between controls and lesioned rats at 2 months after injury (Fig. 3d).

\section{The hypoglossal neurograms after $\mathbf{C}_{2}$ hemisection}

In the above section we have described an effect of $\mathrm{C}_{2}$ hemisection on the amplitude response in the contralateral phrenic neurogram that develops between 1 and 2 months after injury. Some rostral VRG bulbospinal premotor neurons with bilateral projections to the phrenic nuclei also project to the ipsilateral hypoglossal nucleus (Lipski et al., 1994). It follows that a $\mathrm{C}_{2}$ hemisection could potentially alter respiratory motor output from both hypoglossal nuclei. To examine this hypothesis, we recorded the hypoglossal neurogram response to hypercapnic challenge in all rats at 1 month and eight control and five lesioned rats at 2 months after injury (Fig. 4). The effect of $\mathrm{C}_{2}$ hemisection on neurogram amplitude during hypercapnia 
Table 2. Cardiovascular measurements obtained in control (combined 1 month, $n=13 ; 2$ month controls, $n=20)$, $C_{2}$ hemisected (1 month, $n=8$; 2 months, $n=15)$, DHT-only $(n=7)$, and DHT $+C_{2}$ hemisected $(n=10)$ rats

$\mathrm{C}_{2}$ hemisected

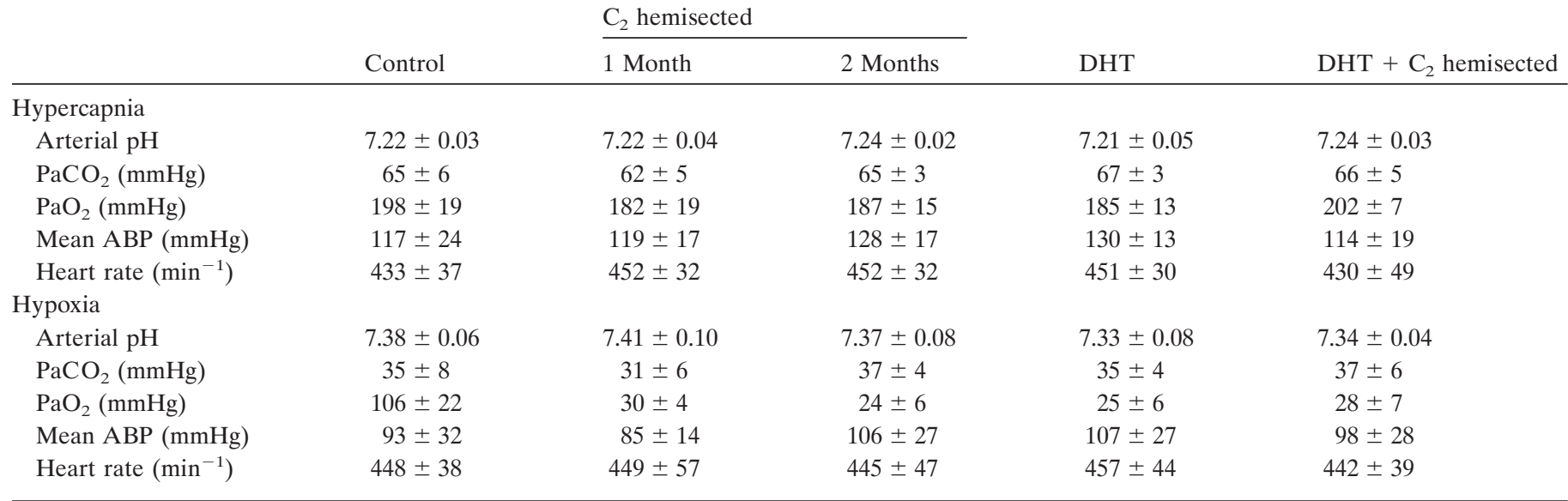

Means \pm SD.

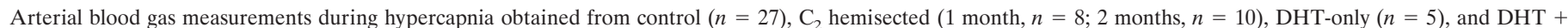

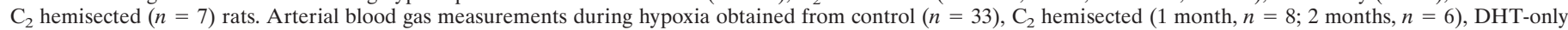
$(n=4)$, and DHT $+\mathrm{C}_{2}$ hemisected $(n=4)$ rats.
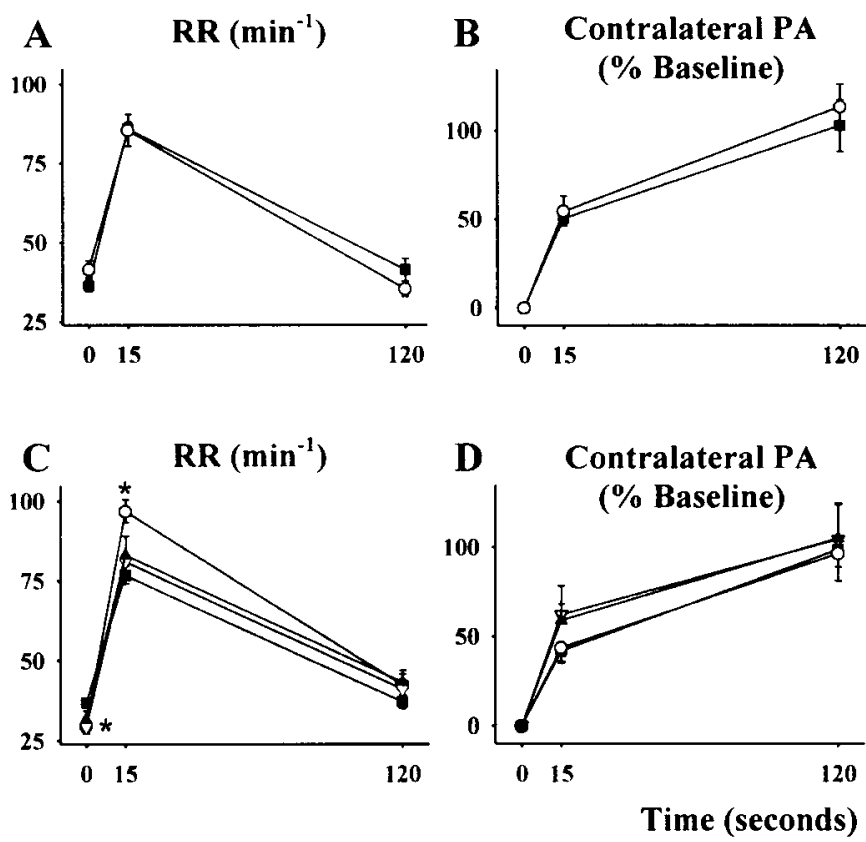

Figure 3. The contralateral phrenic neurogram response to hypoxic challenge. The response to hypoxia is presented at 1 month $(A, B)$ and 2 months $(C, D)$ after injury in control $(\square)$, DHT-only $(\nabla), \mathrm{C}_{2}$ hemisected $(\bigcirc)$, and DHT $+\mathrm{C}_{2}$ hemisected $(\boldsymbol{\Delta})$ rats. $A$ and $C$ represent the change in respiratory rate (RR) during 2 min of hypoxia. $B$ and $D$ represent the percentage of increase in phrenic amplitude (PA) from baseline in the contralateral phrenic nerve. Means $\pm \mathrm{SE} ;{ }^{*} p<0.05 \mathrm{C}_{2}$ hemisected group relative to control.

also was evident in both hypoglossal nerves and again only occurring at 2 months after injury (Fig. 4b).

\section{The ipsilateral phrenic neurogram after $\mathbf{C}_{2}$ hemisection}

Spontaneous functional recovery has been previously reported to occur in the phrenic nerve ipsilateral to the side of injury by 1-2 months after $\mathrm{C}_{2}$ hemisection (Nantwi et al., 1999). Examination of the raw and integrated neurograms from the ipsilateral phrenic nerve revealed similar findings in the present study. Interestingly,

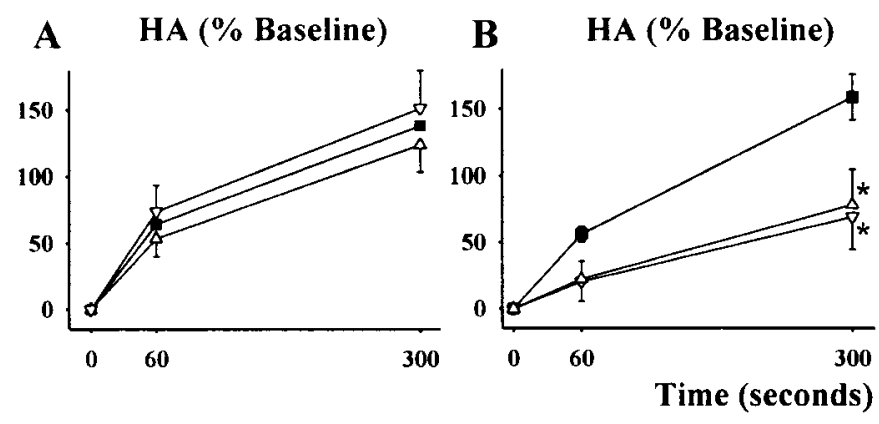

Figure 4. The hypoglossal neurogram amplitude response to hypercapnia. The amplitude response is presented at 1 month $(A)$ and 2 months $(B)$ after injury from both hypoglossal nerves in control rats $(\mathbf{\square})$, and the ipsilateral $(\nabla)$ and contralateral $(\triangle)$ hypoglossal nerves in $\mathrm{C}_{2}$ hemisected rats. $H A$, Hypoglossal neurogram inspiratory amplitude as a percentage of baseline. ${ }^{*} p<0.05$ relative to control.

the onset of the ipsilateral and contralateral changes in respiratory motor output after $\mathrm{C}_{2}$ hemisection occurred within the same time frame. Functional recovery was considered present if there was evidence of phasic bursting in synchrony with inspiratory activity in the contralateral phrenic neurogram (Fig. 5a). When activity was present at baseline and during subsequent respiratory challenges, it was visibly reduced in amplitude relative to the contralateral phrenic neurogram (Fig. $5 a$ ). Functional recovery in the ipsilateral phrenic nerve was seen in two of eight $\mathrm{C}_{2}$ hemisected rats during baseline conditions at 1 month after injury. This was significantly lower than the incidence of recovery at 2 months after injury (11 of 15 rats) $(p<0.05)$.

At 1 month after injury, four of the remaining six rats developed phasic inspiratory activity during hypercapnia, which was reversible when returned to baseline conditions and then returned for subsequent challenges (hypoxia and asphyxia). The remaining two rats developed phasic inspiratory activity during hypoxia, which also was reversible and reappeared during asphyxia. At 2 months after injury, three of the four $\mathrm{C}_{2}$ hemisected rats that did not have activity in the ipsilateral phrenic nerve during baseline conditions developed phasic inspiratory bursting during hypercapnia, and this was reversible when the rats were returned to 

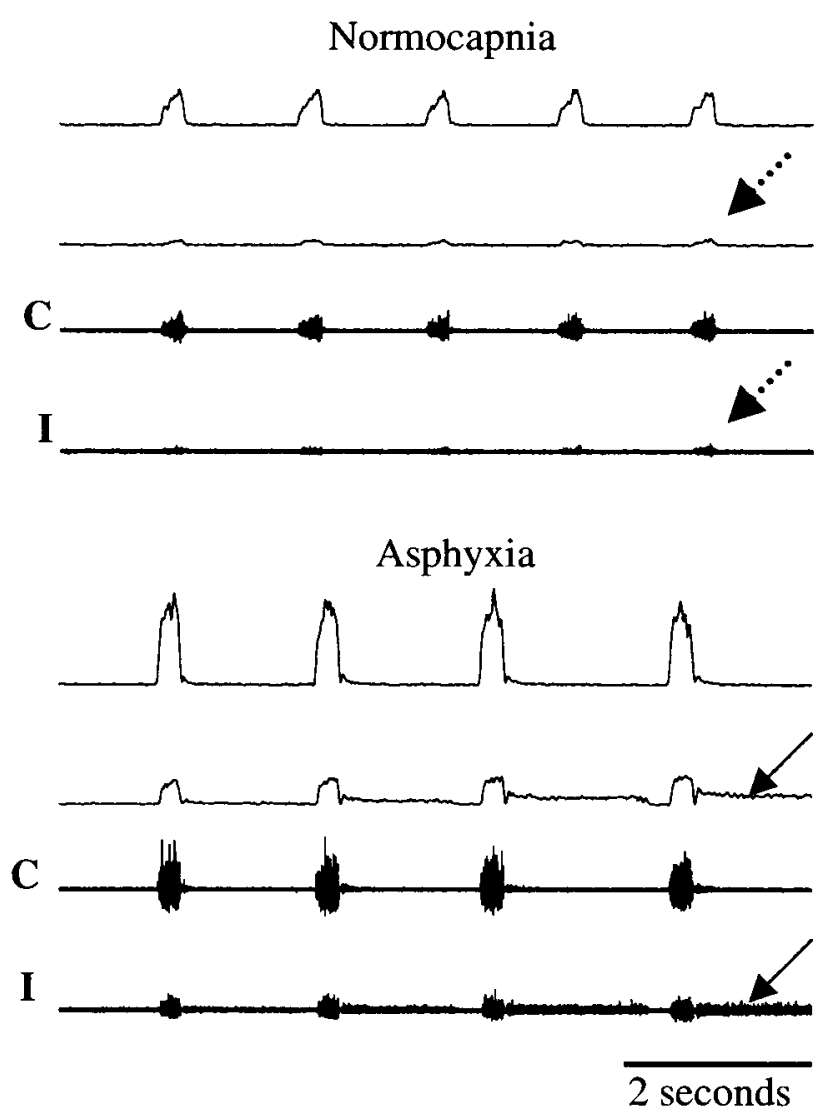

Figure 5. Integrated (top) and raw (bottom) neurograms from the contralateral $(C)$ and ipsilateral $(I)$ phrenic nerves in a $\mathrm{C}_{2}$ hemisected rat at 2 months after injury during normocapnia and asphyxia. Vertical scales (in millivolts) are the same for all traces. Note the presence of synchronous phasic inspiratory activity in the ipsilateral phrenic nerve (dotted arrows) and increased tonic activity during the expiratory phase in the ipsilateral but not the contralateral phrenic neurogram (solid arrows).

baseline conditions and subsequent challenges (hypoxia and asphyxia) thereafter. In one rat, no evidence of spontaneous recovery was evident throughout the study.

Previous investigations have primarily focused on changes in inspiratory discharge in the ipsilateral phrenic nerve after $\mathrm{C}_{2}$ hemisection (Hadley et al., 1999b; Zhou and Goshgarian, 1999; Nantwi et al., 1999). We examined the expiratory phase in the raw neurograms, which revealed differences between the ipsilateral and contralateral phrenic neurogram in the injured rats that were not present in the controls (Fig. $5 b$ ). At 1 month after injury, tonic activity during the expiratory phase in the ipsilateral phrenic neurogram of $\mathrm{C}_{2}$ hemisected rats was present during hypoxia and asphyxia in one rat. At 2 months after injury, the incidence of this activity was significantly higher than at 1 month (13 of 15 rats).

\section{Serotonergic contribution to the altered contralateral and ipsilateral phrenic neurograms after $\mathbf{C}_{2}$ hemisection at $\mathbf{2}$ months after injury}

Brainstem and spinal serotonin immunoreactivity

To examine the role of serotonin-containing neurons in the emergence of the alterations seen after hemisection, we restricted the second series of experiments in rats at the 2 month postinjury interval. The distribution of serotonergic elements of both brainstem (Fig. 6a) and spinal levels (Fig. $6 c$ ) in normal and sham- operated rats was consistent with previous detailed descriptions (Steinbusch, 1981).

In $\mathrm{C}_{2}$ hemisected rats, brainstem serotonin immunoreactivity was similar to normal and sham-operated rats (data not shown). However, the $\mathrm{C}_{4}$ spinal level in $\mathrm{C}_{2}$ hemisected rats was characterized by an almost complete absence of immunoreactivity in the ipsilateral dorsal and ventral horn compared with normal rats (Fig. 6e). On the contralateral side, immunoreactive beaded axonal profiles were present in the dorsal and ventral horns, but the staining intensity and apparent number of serotonin profiles appeared less than normal (Fig. 6e). In the contralateral ventral horn, varicosities retained their normal distribution around motoneurons.

The effects of DHT on serotonin-containing neurons in the brainstem and spinal cord were consistent with previous studies (Baumgarten et al., 1973, 1974; Maxwell and Foster, 1991). In DHT-treated rats, immunoreactive cell bodies were present in four of seven rats, and the overall intensity of staining appeared less than normal (Fig. 6b). In addition, beaded axonal profiles were reduced in number and staining intensity in all DHT-treated rats, but they persisted in the region of inferior olivary nucleus and NTS. In rats pretreated with DHT and then $\mathrm{C}_{2}$ hemisected, the pattern of serotonin immunoreactivity in the brainstem (data not shown) and $\mathrm{C}_{4}$ spinal segment (Fig. $6 f$ ) were indistinguishable from those rats that had only received DHT.

\section{Brainstem and spinal serotonin levels}

The effects of DHT and/or $\mathrm{C}_{2}$ hemisection on monoamine concentration in the brainstem and cervical spinal cord were assessed using HPLC and mass spectrometric analysis in parallel groups of rats that were not included in terminal electrophysiological studies but that had a similar 2 month postlesion period. The neurotoxin, DHT, has the potential to injure both serotonergic and noradrenergic fibers. Therefore, we assayed for norepinephrine (NE), serotonin, and its metabolite, 5-hydroxyindolacetic acid in the brainstem and cervical spinal cord (Table 3). When monoamine concentration was below the minimal detectable level for any sample during HPLC/mass spectrometric quantification, the value assigned to the animal from which the sample was obtained was defined as the minimum concentration. Assigning a value equal to or greater than the true value provides complete sets of numerical values and allowed comparison of means between groups. This approach has the disadvantage of increasing the chance of a type II error but reduces the likelihood of a type I error. There were no differences in the concentrations of monoamines in normal and sham-operated rats, and we grouped those data as controls. Previous administration of desipramine to block DHT uptake into noradrenergic nerve terminals (Bjorklund et al., 1975) did not affect NE concentration between DHT and control groups (Table 3). No evidence for decreased serotonin concentration was found in the brainstem between groups (Table 3 ) despite the clear loss of immunoreactive fibers as noted above. In contrast, a combined loss of serotonin immunoreactivity and decreased serotonin concentration existed in the cervical spinal cord in groups that received DHT compared with controls $(p<$ 0.05) (Table 3).

\section{Physiological effects of 5,7-dihydroxytryptamine on the contralateral phrenic neurogram}

Baseline arterial $\mathrm{PCO}_{2}$ and contralateral phrenic neurogram amplitude (as a percentage of asphyxic maximal) in rats that had received DHT were similar to control and $\mathrm{C}_{2}$ hemisection-only 

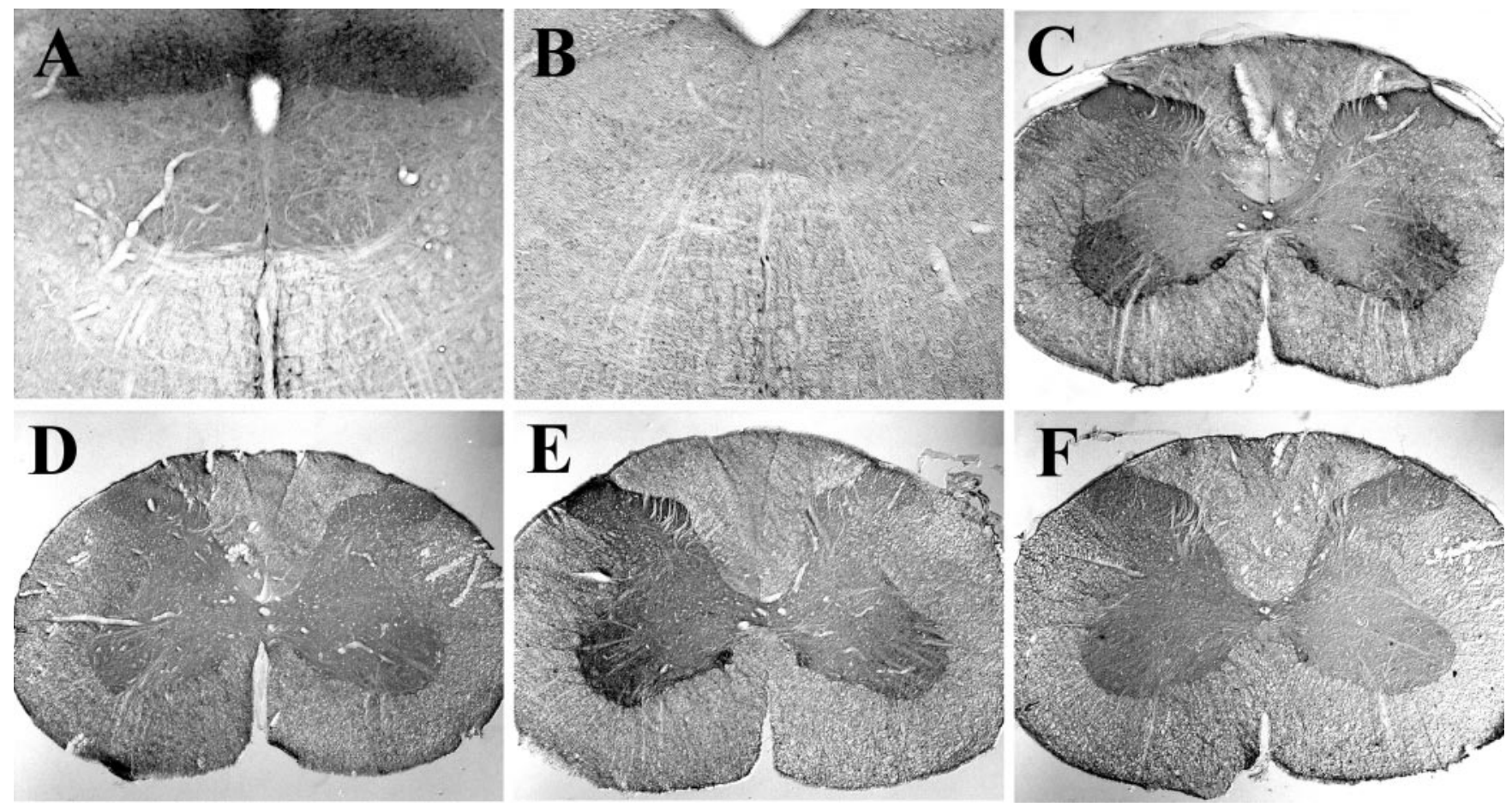

Figure 6. Photomicrographs of sections showing relative serotonin immunoreactivity from the caudal brainstem in normal $(A)$ and DHT-only $(B)$ rats, and the $\mathrm{C}_{4}$ spinal segment in normal $(C)$, DHT-only $(D), \mathrm{C}_{2}$ hemisected $(E)$, and DHT and $\mathrm{C}_{2}$ hemisected $(F)$ rats. Notice the paucity of immunoreactive cells (midline of each brainstem section) and varicosities (top aspect of each brainstem section) in rats that had received DHT. Also notice the bilateral distribution of immunoreactive varicosities in the $\mathrm{C}_{4}$ spinal sections from the normal rat $(C)$ and the loss of immunoreactivity on the side of injury in the $\mathrm{C}_{2}$ hemisected rat $(D)$. Both uninjured and injured rats that had received DHT had only sparse immunoreactive varicosities $(D, F)$.

Table 3. Concentrations of norepinephrine (NE), serotonin (5-HT), and its metabolite 5-hydroxyindolacetic acid (5-HIAA) in brainstem and cervical spinal cord determined by HPLC/mass spectrometric analysis at 2 months after injury

\begin{tabular}{|c|c|c|c|c|c|c|}
\hline & \multicolumn{3}{|c|}{ Brainstem } & \multicolumn{3}{|c|}{ Cervical spinal cord } \\
\hline & $\begin{array}{l}\mathrm{NE} \\
(\mu \mathrm{g} / \mathrm{gm})\end{array}$ & $\begin{array}{l}5 \text {-HT } \\
(\mu \mathrm{g} / \mathrm{gm})\end{array}$ & $\begin{array}{l}\text { 5-HIAA } \\
(\mu \mathrm{g} / \mathrm{gm})\end{array}$ & $\begin{array}{l}\mathrm{NE} \\
(\mu \mathrm{g} / \mathrm{gm})\end{array}$ & $\begin{array}{l}5-\mathrm{HT} \\
(\mu \mathrm{g} / \mathrm{gm})\end{array}$ & $\begin{array}{l}\text { 5-HIAA } \\
(\mu \mathrm{g} / \mathrm{gm})\end{array}$ \\
\hline Control $(n=7)$ & $5.3 \pm 1.2$ & $0.28 \pm 0.12$ & $0.22 \pm 0.09$ & $4.0 \pm 1.8$ & $0.17 \pm 0.05$ & $0.21 \pm 0.03$ \\
\hline DHT-only $(n=5)$ & $4.6 \pm 1.6$ & $0.23 \pm 0.09$ & $0.24 \pm 0.19$ & $3.1 \pm 0.9$ & $0.09 \pm 0.04^{*}$ & $0.24 \pm 0.01$ \\
\hline $\mathrm{C}_{2}$ hemisected $(n=5)$ & $3.9 \pm 1.1$ & $0.28 \pm 0.27$ & $0.31 \pm 0.10$ & $3.3 \pm 1.3$ & $0.11 \pm 0.05$ & $0.28 \pm 0.05$ \\
\hline $\mathrm{C}_{2}$ hemisected + DHT $(n=5)$ & $4.1 \pm 2.1$ & $0.17 \pm 0.14$ & $0.22 \pm 0.10$ & $3.1 \pm 1.4$ & $0.09 \pm 0.02 *$ & $0.23 \pm 0.05$ \\
\hline
\end{tabular}

Values are reported as means \pm SD.

${ }^{*} p<0.05$ relative to control.

groups (Table 1). In general agreement with other studies (Mueller et al., 1980, 1985; Martin-Body and Grundy, 1985; Kamei et al., 1988), rats that received DHT had a significantly lower baseline RR compared with controls $(p<0.05)$ (Table 1$)$. Although $\mathrm{C}_{2}$ hemisection had a similar effect on baseline RR, the combination of DHT and injury did not appear to be additive (Table 1).

In the DHT-only group, the contralateral phrenic neurogram responses to hypercapnia and hypoxia were not altered compared with control rats (Figs. $2 c, d, 3 c, d$ ). However, the neurotoxin did modify the hypercapnic response in $\mathrm{C}_{2}$ hemisected rats. During hypercapnia, the percentage of change in phrenic neurogram amplitude contralateral to the side of injury in DHT $+\mathrm{C}_{2}$ hemisected rats was significantly higher than $\mathrm{C}_{2}$ hemisected rats $(p<0.05)$ and not different from controls (Fig. $2 d)$. Unlike the hemisection-only group during early hypoxia, the RR in the $\mathrm{DHT}+\mathrm{C}_{2}$ hemisected group was not different to the controls (Fig. 3c).

\section{Physiological effects of 5,7-dihydroxytryptamine on the ipsilateral phrenic neurogram}

The incidence of spontaneous functional recovery at 2 months after injury was $73 \%$ in $\mathrm{C}_{2}$ hemisected rats, and this decreased to only $20 \%$ in injured rats pretreated with DHT $(p<0.05)$. The incidence of unilateral tonic activity during the expiratory phase in $\mathrm{C}_{2}$ hemisected rats (87\%) also was significantly lower than in $\mathrm{C}_{2}$ hemisected rats that were pretreated with DHT (40\%) $(p<$ $0.05)$.

\section{DISCUSSION}

This investigation has revealed new insights about the range of neuroplasticity that can be induced in the PhMN system after SCI by demonstrating for the first time a contralateral effect of a spinal cord hemisection on phrenic neurogram amplitude, as well as a bilateral supraspinal effect on the control of breathing. These responses were not present until 2 months after injury-a time 
when a modest spontaneous recovery of ipsilateral PhMN function was also first seen. Finally, we present data suggesting that these effects of spinal hemisection on respiratory motor output may be mediated in part by serotonin-containing neurons. Together, these results provide a basis for gaining further information about the neurobiological mechanisms of respiratory control via a high cervical spinal injury paradigm.

\section{Altered respiratory motor output}

Considering the similarity between groups in normalized baseline amplitude, we conclude that the altered neurogram amplitudes (Figs. $2 d, 4 b$ ) in $\mathrm{C}_{2}$ injured rats represent an impairment of respiratory motor output during hypercapnia. Although we cannot completely rule out segmental mechanisms within the contralateral phrenic nucleus (i.e., synaptic plasticity; Tai and Goshgarian, 1996; Hadley et al., 1999a; Zhou and Goshgarian, 1999), the hypoglossal data imply a primary or concomitant supraspinal manifestation of functional plasticity. Furthermore, the changes in respiratory rate after injury (Figs. $2 c, 3 c$ ) also support a supraspinal effect of $\mathrm{C}_{2}$ hemisection on the control of breathing.

These data suggest that either common segmental and supraspinal mechanisms are involved or that physiological and/or functional reorganization is occurring over the course of 2 months within or extrinsic to the premotor neurons. It is conceivable, for example, that $\mathrm{C}_{2}$ hemisection can precipitate functional reorganization at the level of brainstem as a consequence of bulbospinal axotomy (Bernstein-Goral et al., 1997; Chen and Tseng, 1997; Jain et al., 2000; Wang et al., 2000). In particular, some rostral VRG respiratory premotor neurons project collaterals to the hypoglossal and phrenic nuclei (Lipski et al., 1994), and axons from respiratory raphe neurons have a similar distribution (Manaker et al., 1992). Injury-induced plasticity in these brainstem neurons could account for the changes in motor output seen at 2 months after injury. Alternatively, axotomy to premotor neurons could alter their intrinsic electrophysiological properties over time (Tseng and Prince, 1996; Chen and Tseng, 1997; Wang et al., 2000).

$\mathrm{C}_{2}$ hemisection also may damage ascending spinobulbar projections (Hubscher and Johnson, 1999) and interrupt afferents segmentally via cervical dorsal rhizotomy (CDR). Chronic CDR has been demonstrated to alter respiratory motor output from the phrenic and hypoglossal motoneurons indirectly by profoundly influencing serotonergic plasticity within these motor nuclei (Kinkead et al., 1998; Bach et al., 2000; Mantilla et al., 2000). This may also relate to the DHT findings discussed below.

In humans, cervical SCI alters the hypercapnic and hypoxic ventilatory responses by increasing minute ventilation using a higher RR and lower tidal volume than normals (Pokorski et al., 1989; Gorini et al., 2000). In rats with a thoracic contusive injury, an elevated RR also occurs during hypercapnia (Teng et al., 1999). This most likely reflects vagal matching of RR and tidal volume; however, the contribution from a supraspinal effect cannot be ruled out. It is unlikely that respiratory mechanical variables contributed to our findings because rats were vagotomized and neuromuscularly paralyzed.

Arterial blood gases were similar between groups throughout our study, indicating that the levels of chemoreceptor challenge were standardized. The stimulus-specific nature of the $C_{2}$ injury on neurogram amplitude via the contralateral phrenic nerve suggests a differential effect of injury on the neural response to chemoreceptor challenge. Hypercapnic and hypoxic stimuli use a common bulbospinal pathway, suggesting that the injury effects occur presynaptically to premotor neurons. The effects of $\mathrm{C}_{2}$ hemisection on the chemoreception of arterial $\mathrm{CO}_{2}$ and of oxygen are unknown. Although the apneic threshold was similar between groups, we did not measure minute ventilation in this study. However, in a spontaneously breathing preparation, injured rats are able to maintain the same minute ventilation as controls with similar $\mathrm{PaCO}_{2}$ (Golder et al., 2001). An enhanced sensitivity to $\mathrm{PaO}_{2}$ could explain the decreased baseline RR during hyperoxia and increased $\mathrm{RR}$ during hypoxia in injured rats. Changes in the sensitivity to $\mathrm{PaO}_{2}$ may occur at either the carotid bodies (Prabhakar, 2001) or the central signaling pathway (Gozal et al., 2000).

Increased tonic activity in the ipsilateral phrenic nerve during the expiratory phase in injured rats has been described elsewhere (O'Hara and Goshgarian, 1991). Interestingly, a similar effect is seen in ipsilateral external intercostal motoneurons after thoracic hemisection (Kirkwood et al., 1984). This activity has been attributed to loss of inhibitory afferent drive or increased excitability of the motoneurons after hemisection (Kirkwood et al., 1984).

\section{Similar onset of contralateral and ipsilateral phrenic plasticity}

It was of interest to find that the contralateral and supraspinal effects of $\mathrm{C}_{2}$ hemisection coincided with an onset of a limited recovery of ipsilateral PhMN function. The incidence of spontaneous recovery increased from 25 to $73 \%$ between 1 and 2 months, which is in general agreement with the findings of Nantwi et al. (1999). In addition, phasic bursting could be reversibly induced during hypercapnia when there was no evidence of such activity before the challenge. This also is consistent with a previous report (Zhou and Goshgarian, 1999) and supports the hypothesis that spontaneous recovery involves the recruitment of previously silent pathways (Nantwi et al., 1999). A similar onset time of functional plasticity in the ipsilateral and contralateral PhMN pools suggests that both events may share a common mechanism. For example, functional recovery in the ipsilateral hemidiaphragm could result in decreased motor output in the contralateral phrenic nerve via renewed inhibitory phrenic afferent feedback (Frazier and Revelette, 1991) and respiratory plasticity (Goshgarian, 1981) in the contralateral phrenic nerve. Renewed motor activity after spontaneous functional recovery in the paralyzed hemidiaphragm may enhance ipsilateral phrenic afferent discharge, which could inhibit motor output in the contralateral phrenic nerve. The effect of these afferents on hypoglossal output is unknown; however, a supraspinal influence of phrenic afferents has been described (Speck, 1987).

\section{The role of serotonin-containing neurons}

Interpretation of the effects of DHT on the supraspinal control of respiratory motor output in our study is subject to the caveat that this compound can decrease other colocalized neuromodulators such as thyroid-releasing hormone, adrenocorticotrophic hormone, and substance $\mathrm{P}$, as well as regeneration of serotonergic innervation in supraspinal structures and receptor supersensitivity throughout the CNS (Baumgarten et al., 1974; Pranzatelli, 1998). Therefore, interpretation of our results is restricted to plasticity of serotonin-containing neurons and not specifically to serotonin itself.

We found no evidence for decreased serotonin concentration in the brainstem in any group despite the loss of immunoreactive fibers in rats that had received DHT. Others have also demon- 
strated a greater effect of DHT on the distribution of serotoninimmunoreactive fibers within the brainstem rather than serotonin concentration (Baumgarten et al., 1973, 1974). In contrast, we demonstrated decreased serotonin immunoreactivity and serotonin concentration within the cervical spinal cord in groups that received DHT. This also was consistent with other studies (Baumgarten et al., 1973, 1974). Collectively, these results indicate that DHT led to plasticity of serotonin-containing neurons within the brainstem and serotonergic innervation on both sides of the cervical spinal cord; however, some recovery of serotonin concentration had occurred supraspinally by 2 months.

Pretreatment of $\mathrm{C}_{2}$ hemisected rats with DHT normalized both the contralateral phrenic neurogram amplitude response during hypercapnia (Fig. $2 d$ ) and the change in respiratory rate during hypoxia (Fig. 3c) at 2 months after injury. This suggests that serotonin-containing neurons may contribute to these effects. Serotonin 5-HT1a receptors have been demonstrated to have both supraspinal and spinal inhibitory effects on respiratory motor output (Lindsay and Feldman, 1993; Richmonds and Hudgel, 1996; Di Pasquale et al., 1997), as well as increasing respiratory rate at the level of the brainstem (Monteau et al., 1994; Richmonds and Hudgel, 1996; Hilaire et al., 1997). A $\mathrm{C}_{2}$ injury may alter supraspinal control of breathing partly via activation of 5-HT1a receptors in the brainstem.

Plasticity of serotonin-containing nerve terminals may contribute to the CPP after $\mathrm{C}_{2}$ hemisection injury (Ling et al., 1994; Tai et al., 1997; Hadley et al., 1999a). The role of serotonin in spontaneous recovery of the ipsilateral phrenic nerve is unknown, however considerable evidence suggests that serotonin-mediated plasticity does occur within the phrenic nucleus secondary to cervical SCI (Tai et al., 1997; Kinkead et al., 1998; Mitchell et al., 2000). We have demonstrated a decrease in the incidence of spontaneous recovery and tonic activity in the ipsilateral phrenic neurogram in $\mathrm{C}_{2}$ hemisected rats pretreated with DHT. This novel finding suggests that serotonin-containing neurons may in part mediate ipsilateral spontaneous recovery of respiratory activity. As mentioned in the previous section, injury may induce ipsilateral and contralateral phrenic plasticity via a common mechanism. This hypothesis is supported by our experiments with DHT because the neurotoxin reduced both forms of plasticity in injured rats.

\section{REFERENCES}

Bach KB, Mitchell GS (1998) Hypercapnia-induced long-term depression of respiratory activity requires alpha2-adrenergic receptors. J Appl Physiol 84:2099-2105.

Bach KB, Mitchell GS (2000) Effects of phrenicotomy and exercise on hypoxia-induced changes in phrenic motor output. J Appl Physiol 89:1884-1891.

Bach KB, Kinkead R, Mitchell GS (1999). Post-hypoxia frequency decline in rats: sensitivity to repeated hypoxia and alpha2-adrenoreceptor antagonism. Brain Res 817:25-33.

Bach KB, Johnson RA, Kinkead RK, Fuller DD, Zhan W, Mantilla C, Sieck GS, Mitchell GS (2000) Cervical dorsal rhizotomy (CDR) enhances serotonin-dependent long-term facilitation of hypoglossal motor output in rats. FASEB J 14:A77.

Baumgarten HG, Bjorklund A, Lachenmayer L, Nobin A (1973) Evaluation of the effects of 5,7-dihydroxytryptamine on serotonin and catecholamine neurons in the CNS. Acta Physiol Scand [Suppl] 391:1-19.

Baumgarten HG, Bjorklund A, Lachenmayer L, Rensch A, Rosengren E (1974) De- and regeneration of the bulbospinal serotonin neurons in the rat following 5,6-or 5,7-dihydroxytryptamine treatment. Cell Tissue Res 152:271-281.

Bellingham MC, Lipski J (1990) Respiratory interneurons in the C5 segment of the spinal cord of the cat. Brain Res 533:141-146.

Bernstein-Goral H, Diener PS, Bregman BS (1997) Regenerating and sprouting axons differ in their requirements for growth after injury. Exp Neurol 148:51-72.

Bjorklund A, Baumgarten HG, Rensch A (1975) 5,7-Dihydroxy- tryptamine: improvement of its selectivity for serotonin neurons in the CNS by pretreatment with desipramine. J Neurochem 24:833-835.

Bonham AC (1995) Neurotransmitters in the CNS control of breathing. Respir Physiol 101:219-230.

Chen JR, Tseng GF (1997) Membrane properties and inhibitory connections of normal and upper cervically axotomized rubrospinal neurons in the rat. Neuroscience 79:449-462.

Di Pasquale E, Lindsay A, Feldman J, Monteau R, Hilaire G (1997) Serotonergic inhibition of phrenic motoneuron activity: an in vitro study in neonatal rat. Neurosci Lett 230:29-32.

Ellenberger HH, Feldman JL, Goshgarian HG (1990) Ventral respiratory group projections to phrenic motoneurons: electron microscopic evidence for monosynaptic connections. J Comp Neurol 302:707-714.

Frazier DT, Revelette WR (1991) Role of phrenic nerve afferents in the control of breathing. J Appl Physiol 70:491-496.

Fregosi RF, Mitchell GS (1994) Long-term facilitation of inspiratory intercostals nerve activity following carotid sinus nerve stimulation in cats. J Physiol (Lond) 477:469-479.

Fukuda Y, Honda Y (1982) Effects of hypocapnia on respiratory timing and inspiratory activities of the superior laryngeal, hypoglossal, and phrenic nerves in the vagotomized rat. Jpn J Physiol 33:733-742.

Golder FJ, Reier PJ, Davenport PW, Bolser DC (2001) Cervical spinal cord injury alters the pattern of breathing in anesthetized rats. J Appl Physiol, in press.

Gorini M, Corrado A, Aito S, Ginanni R, Villella G, Lucchesi G, De Paola E (2000) Ventilatory and respiratory muscle responses to hypercapnia in patients with paraplegia. Am J Respir Crit Care Med 162:203-208.

Goshgarian HG (1981) The role of cervical afferent nerve fiber inhibition of the crossed phrenic phenomenon. Exp Neurol 72:211-225.

Gozal D, Gozal E, Simakajornboon N (2000) Signaling pathways of the acute hypoxic ventilatory response in the nucleus tractus solitarius. Respir Physiol 121:209-221.

Hadley SD, Walker PD, Goshgarian HG (1999a) Effects of serotonin inhibition on neuronal and astrocyte plasticity in the phrenic nucleus $4 \mathrm{~h}$ following $\mathrm{C}_{2}$ spinal cord hemisection. Exp Neurol 160:433-445.

Hadley SD, Walker PD, Goshgarian HG (1999b) Effects of serotonin synthesis inhibitor p-CPA on the expression of the crossed phrenic phenomenon $4 \mathrm{~h}$ following $\mathrm{C}_{2}$ spinal cord hemisection. Exp Neurol 160:479-488.

Hilaire G, Bou C, Monteau R (1997) Serotonergic modulation of central respiratory activity in the neonatal mouse: an in vitro study. Eur J Pharmacol 329:115-120.

Hoop B, Beagle JL, Maher TJ, Kazemi H (1999) Brainstem amino acid neurotransmitters and hypoxic ventilatory response. Respir Physiol 118:117-129.

Hubscher CH, Johnson RD (1999) Effects of acute and chronic midthoracic spinal cord injury on neural circuits for male sexual function. I. Ascending pathways. J Neurophysiol 82:1381-1389.

Jain N, Florence SL, Qi HX, Kaas JH (2000) Growth of new brainstem connections in the adult monkey with massive sensory loss. Proc Natl Acad Sci USA 97:5546-5550.

Kamei J, Ogawa M, Kasuya Y (1988) Supersensitivity of 5,7dihydroxytryptamine-treated rats to the respiratory depressant and antitussive effects of dihydrocodeine. Eur J Pharmacol 153:305-308.

Kinkead R, Zhan WZ, Prakash YS, Bach KB, Sieck GC, Mitchell GS (1998) Cervical dorsal rhizotomy enhances serotonergic innervation of phrenic motorneurons and serotonin-dependent long-term facilitation of respiratory motor output in rats. J Neurosci 18:8436-8443.

Kirkwood PA, Sears TA, Westgaard RH (1984) Restoration of function in external intercostal motoneurones of the cat following partial central deafferentation. J Physiol (Lond) 350:225-251.

Kong FJ, Berger AJ (1986) Firing properties and hypercapnic responses of single phrenic motor axons in the rat. J Appl Physiol 61:1999-2004

Lindsay AD, Feldman JL (1993) Modulation of respiratory activity of neonatal rat phrenic motoneurones by serotonin. J Physiol (Lond) 461:213-233.

Ling L, Bach KB, Mitchell GS (1994) Serotonin reveals ineffective spinal pathways to contralateral phrenic motoneurons in spinally hemisected rats. Exp Brain Res 101:35-43.

Lipski J, Zhang X, Kruszewska B, Kanjhan R (1994) Morphological study of long axon projections of ventral medullary inspiratory neurons in the rat. Brain Res 640:171-184.

Manaker S, Tischler LJ, Morrison AR (1992) Raphespinal and reticulospinal axon collaterals to the hypoglossal nucleus in the rat. J Comp Neurol 322:68-78.

Mantilla CB, Moore MJ, Zhan WZ, Bach KB, Mitchell GS, Sieck GC (2000) Plasticity of hypoglossal motoneurons following chronic cervical dorsal rhizotomy in rats. Soc Neurosci Abstr 26:1372.

Martin-Body RL, Grundy HR (1985) Effects of neurotoxin-induced brainstem lesions on the respiratory responses of conscious rats. Clin Exp Pharmacol Physiol 12:427-437.

Maxwell DJ, Foster GA (1991) Immunoelectron microscopic analysis of the synaptic connectivity of serotoninergic neurons grafted to the 
5,7-dihydroxytryptamine-lesioned rat spinal cord. Neuroscience 45:307-321.

McCrimmon DR, Dekin MS, Mitchell GS (1995) Glutamate, GABA, and serotonin in ventilatory control. In: Regulation of breathing (Dempsey JA, Pack AI, eds), pp 1065-1117. New York: Marcel Dekker.

Mitchell GS, Bach KB, Martin PA, Foley KT, Olson EB, Brownfield MS, Miletic V, Behan M, McGuirk S, Sloan HE (2000) Increased spinal monoamine concentrations after chronic thoracic dorsal rhizotomy in goats. J Appl Physiol 89:1266-1274.

Monteau R, Di Pasquale E, Hilaire G (1994) Further evidence that various 5-HT receptor subtypes modulate central respiratory activity: in vitro studies with SR 46349B. Eur J Pharmacol 259:71-74.

Moreno DE, Goshgarian HG (1992) Identification of the axon pathways which mediate functional recovery of the paralyzed hemidiaphragm following spinal cord hemisection in the rat. Exp Neurol 116:219-228.

Mueller RA, Lundberg D, Breese G (1980) Effects of different monoamine oxidase inhibitors on respiratory activity in rats with chronically impaired central serotonergic function. Acta Pharmacol Toxicol (Copenh) 47:285-293.

Mueller RA, Towle AC, Breese GR (1985) The role of vagal afferents and carbon dioxide in the respiratory response to thyrotropin-releasing hormone. Regul Pept 10:157-166.

Nantwi KD, El-Bohy AA, Schrimsher GW, Reier PJ, Goshgarian HG (1999) Spontaneous recovery in a paralyzed hemidiaphragm following upper cervical spinal cord injury in adult rats. Neurorehabil Neural Repair 13:225-234.

O'Hara Jr TE, Goshgarian HG (1991) Quantitative assessment of phrenic nerve functional recovery mediated by the crossed phrenic reflex at various time intervals after spinal cord injury. Exp Neurol 111:244-250.

Pokorski M, Morikawa T, Takaishi S, Masuda A, Ahn B, Honda Y (1989) Paralysis of respiratory muscles and hypoxic ventilatory chemoreflex. Biomed Biochem Acta 48:S573-S577.

Prabhakar NR (2001) Physiological and genomic consequences of intermittent hypoxia, invited review: oxygen sensing during intermittent hypoxia: cellular and molecular mechanisms. J Appl Physiol 90:1986-1994.
Pranzatelli MR (1998) Use of 5 6-, 5:7-dihydroxytryptamine to lesion serotonin neurons In: Highly selective neurotoxins: basic and clinical applications (Kostrzewa RM, ed), pp 293-311. New Jersey: Humana.

Richmonds CR, Hudgel DW (1996) Hypoglossal and phrenic motoneurons responses to serotonergic active agents in rats. Respir Physiol 106:153-160.

Speck DF (1987) Supraspinal involvement in the phrenic-to-phrenic inhibitory reflex. Brain Res 414:169-172.

St. John WM, Paton JFR (2000) Characterizations of eupnea, apneusis and gasping in a perfused rat preparation. Respir Physiol 123:201-213.

Steinbusch HW (1981) Distribution of serotonin-immunoreactivity in the central nervous system of the rat-cell bodies and terminals. Neuroscience 6:557-618.

Tai Q, Goshgarian HG (1996) Ultrastructural quantitative analysis of glutamatergic and GABAergic synaptic terminals in the phrenic nucleus after spinal cord injury. J Comp Neurol 372:343-355.

Tai Q, Palazzolo KL, Goshgarian HG (1997) Synaptic plasticity of 5-hydroxytryptamine-immunoreactive terminals in the phrenic nucleus following spinal cord injury: A quantitative electron microscopy analysis. J Comp Neurol 386:613-624.

Teng YD, Mocchetti I, Taveira-DaSilva AM, Gillis RA, Wrathall JR (1999) Basic fibroblast growth factor increases long-term survival of spinal motor neurons and improves respiratory function after experimental spinal cord injury. J Neurosci 19:7037-7047.

Tseng GF, Prince DA (1996) Structural and functional alterations in rat corticospinal neurons after axotomy. J Comp Neurol 245:359-378.

Wang YJ, Ho HW, Tseng GF (2000) Fate of the supraspinal collaterals of cord-projection neurons following upper spinal axonal injury. J Neurotrauma 17:231-241.

Zhou SY, Goshgarian HG (1999) Effects of serotonin on the crossed phrenic nerve activity in cervical spinal cord hemisected rats. Exp Neurol 160:446-453.

Zhou SY, Goshgarian HG (2000) 5-Hydroxytryptophan-induced respiratory recovery after cervical spinal cord hemisection in rats. J Appl Physiol 89:1528-1536. 